\title{
A probabilistic framework for assessing spatio-temporal point patterns in the archaeological record
}

\author{
Enrico Crema, Andrew Bevan, Mark Lake
}

Postprint of 2010 paper in Journal of Archaeological Science 37.5: 1118-1130 (doi: 10.1016/j.jas.2009.12.012).

\begin{abstract}
The assessment of spatial patterns in archaeology is hampered by a number of constraints, one of the most serious of which is the intrinsic temporal uncertainty associated with most of the archaeological record. Different types of chronological definition or different degrees of temporal knowledge will suggest different kinds of spatial pattern, ultimately obscuring and restricting our interpretation of the background process, especially in cases where we are seeking a diachronic perspective. This paper addresses these problems by adopting both a probabilistic approach and a more standardised framework for diachronic analysis. First, we define the notion of temporal uncertainty and explore its analytical consequences. Second, we consider two methods by which it might be formally quantified, emphasising a) the advantages of probability-weighted spatial analysis and b) the comparison of alternative spatio-temporal patterns via Monte Carlo simulation. Finally, we apply these methods to a case study that considers the distribution of Middle to Late Jomon (ca.5000-3000 BP) pithouses recorded in the Chiba New Town area of Japan.
\end{abstract}

\section{Introduction}

The application of spatial analysis in archaeology has in most cases relied upon methods adopted from neighbouring disciplines such as geography, ecology and epidemiology. The statistical tools employed in these fields frequently involve a series of assumptions whose importance has been underestimated, if not wholly ignored, in archaeological applications. Point pattern analysis refers to one such group of methods that examines the spatial configuration of point observations across a study area and, potentially ,the underlying process behind its formation. Typically, point pattern analysis assumes that: 1) the spatial pattern in question can be reasonably simplified as a series of zero-dimensional events (points) located in a Euclidean space; 2) the observed point pattern is a sample whose relationship with the overall population can be evaluated; 3 ) the spatial pattern is stationary (i.e. the mean and the variance of the point process is constant within the studied area (Bailey and Gatrell 1995:33); 4) the temporal domain can safely be ignored since all the events are contemporary and do not have variable duration in time. Each of these assumptions have been discussed in the archaeological literature, both from methodological and theoretical perspectives (for general discussions of point pattern analysis: Orton 2005; for the relation between sample and population: Orton 2000; for problems related to non-stationary data: Bevan and Connolly 2009) but surprisingly, despite the presence of debates and proposals for 
possible solutions (Castleford 1992, Daly and Lock 1999, Lock and Harris 2002, Johnson 2004, Bevan and Conolly 2006, etc.) very little effort has been placed on the formal integration of the temporal dimension into practical archaeological analysis.

This paper aims to tackle this pressing issue, by 1) addressing the analytical consequences of temporal uncertainty; 2) proposing new approaches for assessing spatial patterns within a spatio-temporal framework; 3) exploring these issues via an applied case study from prehistoric Japan.

\section{Consequences of Temporal Uncertainty}

Most of the current analytical procedures dealing with time are based on some form of statistical comparison (or informal visual description) of successive, artificial snapshots defined by the researcher. The intrinsic problems associated with this approach are captured in figure 1, where spatio-temporal data is visualized in a three-dimensional space such that $x$ and $y$ correspond to two spatial dimensions and $t$ to the temporal dimension. Each archaeological event (e.g. a site, a feature etc.) is described as a vertical line whose length corresponds to its duration. An archaeologically observed pattern of points (e.g. settlements or artefacts) can be better understood as a projection of the events on the upper face of a time-cube, which is differently defined depending on the nature of our archaeological knowledge. This might be based, for instance, on pottery typology or lithic technology identifying a cultural phase corresponding to a temporal block.

Several problems affect the analysis of any observed pattern defined in this manner. Firstly the projection plane is two-dimensional. Thus any temporal (and therefore by implication, spatial) information bounded within the time-cube is lost or degraded, since the data are treated cumulatively and observed as contemporary. Secondly, the temporal allocations of most events are fuzzy due to the intrinsic uncertainty of archaeological data. As a consequence, the association of an event with a specific time-cube is not always certain. Thirdly, different timecubes often define different projection planes (or snapshots). The direct comparison of different patterns is therefore highly problematic, since each is heavily dependent on the shape of the time-cube. ${ }^{1}$ Lastly, the definition of these time-cubes is often subjective and ambiguous, since each is in fact an artificial subdivision of the time-continuum based on the analyst's preferred method of dating, leading to the observation of potentially different patterns by different analysts.

The visual representation offered in figure 1 demonstrates the problems associated with any straightforward assumptions of synchronicity that often underlie applications of spatial analysis in archaeology, especially those operating with coarse temporal scales or those seeking to understand diachronic processes. Advanced analytical tools that address the temporal dimension directly and that are used in other fields such as ecology and epidemiology (e.g. Knox's index,

\footnotetext{
1 It is worth noting that the time-cube might have different extents both in time and space, for each archaeologically defined period. In fact, relative chronology is often based on characteristics that might have a varying spatial distribution.
} 
Mantel's index, spatio-temporal K Function; see Bailey and Gatrell 1995) are rarely feasible in these archaeological cases, because their core assumption is that we have exact knowledge of the spatial and temporal extent of each event. In other words, these tools do not have the ability to integrate, formally and quantitatively, the uncertainties typical of archaeological data.

The development of alternative approaches is necessary before we can understand archaeological datasets properly. The present paper therefore proposes a probabilistic approach to spatial data analysis that can tackle both the problem of temporal uncertainty for single events and the problem of unequally sized temporal blocks.

\section{Case Study}

For our case study, we consider the western part of the Tokyo Bay area (figure 2), where a number of significant changes in hunter-gatherer settlement patterns can be documented towards the end of the mid-Holocene. In particular, several scholars (Imamura 1996, Habu 2003, Habu 2008 for general references) have noticed abrupt socio-economic, cultural and environmental changes during the transitional phase between the Middle (ca. 5000-4000 BP) and Late (ca. 40003000 BP) Jomon periods. The objective of spatial analysis in this case study is to test the hypothesis proposed by certain authors (e.g. Kano 2002) that an abrupt transformation occurred in the spatial distribution of pithouses during the Kasori EIII pottery phase, in which a pre-existing settlement pattern of pithouses, typically arranged in annular configurations, became disaggregated into sparser and more irregularly-distributed residential units, perhaps due to an increase in residential mobility (see Toizumi 2007 for malacological support of such a hypothesis).

The chronological subdivisions used in this case study are constructed from typological studies of Jomon pottery. On the basis of the quality and the quantity of the diagnostic pottery sherds recovered from excavated contexts, different levels of chronological resolution can be provided for each pithouse, ranging from the sub-phase ( $<50$ year resolution) to the broader period (ca. 1000 year resolution). The duration of these pottery phases has been established via several different sources (Kobayashi 2006, Minami 2002) in order to cover both the Middle and the Late Jomon period and to provide the most reliable absolute chronological sequence possible for each phase. A recent spread of AMS radiocarbon dates and proper calibration has also allowed the creation of a fine-grained chronological sequence for the Middle Jomon period in the south-west of Japan (see Kobayashi 2006), however the same resolution and precision is not available for the subsequent Late Jomon period, and the exact temporal correlation with the southeastern Kanto (where the present study area is located) is not always clear. Thus, in order to provide a long-term assessment of changes in settlement patterns, the chronological sequence proposed by Minami (2002) has been used for the present study. Minami's sequence provides a coarse-grained, pottery-based periodization that allows integration of Late Jomon period. However, this chronology offer dates that are typically ca. 400 years later in absolute terms, than the more reliable 
Kobayashi's sequence. Where available, the relative duration of Middle Jomon pottery phases have been adapted and corrected on the basis of the relative and proportional length offered by Kobayashi. Thus at this stage although the duration of pottery phases appears to be the best one currently achievable, the allocation of these to an absolute time line is more difficult and involves some discrepancies of ca.400-500 years. The authors are aware of the possibility of alternative suggestions for the temporal duration of these pottery phases and also the weakness of a relative chronological framework that is, ultimately, incapable of supporting comparisons with phenomena outside the specific case study. However, in other ways, the study area remains an almost ideal archaeological case where varying levels of temporal knowledge are present, and it is the spatiotemporal assessment of such datasets - rather than the resolution of the debate over the late Middle Jomon settlement pattern transition - that is the main aim of the present study.

The location of individual pithouses is used below as the primary unit of analysis because it avoids the often-problematic ontological definition of an 'archaeological site' that might exist were we adopt a coarser spatial scale and consider larger aggregates of pithouses as individual observations. The areas formally explored by open area excavation have been used as window of analysis in cases where edge correction formulae are a part of the statistical methods we deploy.

The total extent of the study area considered here is ca.605 ha, of which $14 \%$ has been extensively excavated. A total of 386 published pithouses (see Appendix A for references) can be attributed to the Middle and Late Jomon periods and used for the present analysis, and a smaller study area within this, of low temporal uncertainty (see below), has further been selected for some steps in the analysis.

\section{Quantifying Uncertainty}

The application of probabilistic weighting is probably the most straightforward solution to some of the problems raised in the theoretical discussion above. The core concept behind this approach is that, rather than date an archaeological event $e$ with absolute certainty of presence or absence at a particular time-step, we can define a more flexible existence value $w$, that ranges somewhere between 0 (absolute certainty of non-existence) and 1 (absolute certainty of existence) in a temporal snapshot whose duration is defined by $\Delta t$ The value of $\Delta t$ will assume a central role since, all other things being equal, $w$ will be positively correlated with it, and higher values will therefore be associated with coarser temporal granularity (higher $\Delta \mathrm{t}$ ).

Several alternative methods for the definition of $w$ have been proposed in the literature. For instance, Lock and Harris (2002) based their method on the integration of different sources of time definition, each providing an independent attribution of the value $w$. Thus, for instance, the probability of existence of a site $x$ at time $t_{n}$ might have a value of 0.9 according to radiocarbon dating, 0.5 according to the pottery typology based relative chronology and 0.6 according to other artefact-based dating. The final $w$ of the specific site (called $p$ (use)-values in the 
original paper) is defined either by: 1) the use of a simple average, 2) the use of a weighted average, or the 3 ) the choice of the highest value for the specific period. Since the weighting process is conducted for each temporal snapshot, the total sum of $w$ across all the time steps can be bigger than 1 if the existence of the event extends across more than one time step.

The aoristic weighting method proposed by Ratcliffe (2000), and introduced into archaeology by Johnson (2004), provides a deeper methodological insight into the actual computation of $w$. The main concept in this case is the time span of an event, which is defined as the chronological range within which the event has occurred. In archaeology the boundaries of this will be determined by a terminus ante quem and a terminus post quem. All other things being equal (e.g. ignoring the duration of the event), different events will have different time spans according to the quality of our temporal knowledge: larger time-spans will be created where there is high uncertainty and shorter time-spans with the uncertainty is lower. By assuming that the event is either instantaneous or has a duration which can be considered marginal in comparison to $\Delta t$, aoristic analysis simply provides a value which represents the probability of existence for each defined temporal block $t_{n}$. This is obtained by the following equation:

$$
w_{e}\left(t_{n}\right)=\frac{\Delta t}{\left(\beta_{e}-\alpha_{e}\right)}
$$

where $w$ is the aoristic weight of the event $e$ at time $t_{n}, \Delta t$ is the temporal resolution (the duration of each time block), and $b$ and $a$ the terminus ante and post quem respectively, with all values rounded to the temporal resolution. Aoristic analysis assumes an equal distribution of possible existence across time, thus two events having identical temporal spans will yield the same $w$ for each of their temporal blocks. This can have some negative consequences when a large portion of the sample data have the same temporal spans and occupy the same temporal blocks, because the resulting aoristic analysis will suggest an apparent "homogeneity" across time that is in fact a consequence of the temporal structure of the data, rather than a real feature of the process under investigation (see below for an example).

An additional property, and a necessary precondition, of aoristic analysis is that the value $W_{e}$, corresponding to the sum of all the aoristic weights $w_{1} \ldots w_{t}$ of a single event across its time steps $t$, must be equal to 1 . This condition differs from the properties of the method devised by Lock and Harris (2002), where such value can exceed or be minor than 1 .

This aoristic approach brings both advantages and disadvantages: for example, it is unable to combine, quantitatively and formally, multiple sources of temporal knowledge,in contrast to the method proposed by Lock and Harris that can manage multiply structured and complex datasets, since there are no restriction on the value of $W_{e}$. The weakness, and at the same time the strength, of the Lock and Harris approach is therefore the absence of formality in the weight attribution process. On one hand, this provides the opportunity to handle 'intuitive 
knowledge' (Lock and Harris 2002) in association with, for example, formal radiocarbon probability distributions, but on the other hand, the subjective approach might produce biases that could lead to artificial trends in the spatiotemporal distribution.

Our case study adopts a resolution of 40 time-steps each of 50 years duration, starting with period $t_{1}$ corresponding to $2900 \mathrm{BC}$ and ending with $t_{40}=950 \mathrm{BC}$ on the basis of Minami's scheme. As stated above, this should be taken as the relative chronological length of each pottery phase and not as an absolute dating scheme, since, for instance, time step to is $2500 \mathrm{BC}$ according to Minami and 2950BC according to Kobayashi. The adoption of a 50 year resolution is a pragmatic but empirically justifiable choice which measures the approximate and rounded duration of pottery phases and allows us to ignore the varying lifespans of individual pithouses (available ethnographic analogies suggest that the latter were probably much shorter than our chosen temporal resolution: see Watanabe 1986). From an interpretative perspective, our analysis will focus on the specific moment in time when the residential units were constructed and will aim to assess the spatial structure of this relative locational choice.

Figure 3a demonstrates how the simple sum of aoristic values for each temporal block can improve our knowledge of pithouse density and offer a more formal diachronic framework. Without the aoristic weighting we are forced to find the optimal balance between the chronological resolution and the sample size, with a range of possible combinations from the coarsest temporal resolution/largest sample size to the finest chronological resolution/smallest sample size. Figure $3 \mathrm{~b}$ shows an example of such a representation that is limited by: 1) the choice of a 'sample' (in this case of 59.8\%) of the total available data; 2) a chronological framework entirely based on pottery phases, each with a different absolute chronological length. The aoristic approach, on the other hand, provides regular chronological breaks (in this case equal to $50 \mathrm{yrs}$ ) and integrates probabilistically our information about the entire original sample, providing the best platform for a diachronic assessment. Dynamics which were previously invisible, such as the slight decrease of pithouse numbers within the Middle Jomon peak $\left(t_{10}\right)$ can now be observed and quantified.

Interestingly, the sum of aoristic values illustrates the problem arising from an equal distribution of temporal spans and the resulting difficulty of discerning patterns in cases where the time-spans and weights assigned to each observation are very similar (see above). This is clearly visible for the time-steps $t_{21}$ to $t_{22}$, where most of the events are characterized by an aoristic weight of 0.5 for each time step. Changes between the two time steps appear to be minimal, but this apparent stasis is a direct result of the aoristic distribution (and our current chronological resolution), rather than an indication that there really is no change over these temporal phases.

\subsection{Assessing Patterns of Uncertainty}


The distribution of aoristic weights is, in many instances, likely to be inhomogeneous in both spatial and temporal terms, with the possibility of clusters of 'high' knowledge at particular points in time and space where the quality of data is unusually good. Since the patterns discernable from aoristic weighting reflect a combination of both the unequal distribution of our temporal knowledge and the actual pattern, our assessment of the former will be central for our understanding of the latter. For example, the general decrease in the total aoristic value for the Late Jomon period (figure $3, t_{20}-t_{40}$ ) might be a consequence of either lower actual numbers of pithouses or lower levels of temporal knowledge (i.e. longer timespans). For certain types of analysis, a critical assessment of the actual spatiotemporal process requires an even distribution of knowledge in both dimensions and thus the detection of clusters of low knowledge will assume a central role in developing a sampling strategy capable of producing optimal data sets.

For a simple temporal but aspatial case, the assessment of patterns of uncertainty can be conducted via descriptive analysis of the distribution of aoristic weights at each time step. In most archaeological contexts with large temporal spans, the high frequency of low aoristic values is likely to produce a skewed and/or a bimodal distribution. For a diachronic study, there are also likely to be patterns of temporal autocorrelation in the aoristic weights, since the probabilistic approach distributes the probability values in adjacent time blocks. The diachronic pattern of knowledge and uncertainty can be easily measured by plotting summary statistics for the aoristic weights (such as the average or the median) as a time-series. The case study (fig.4) shows a pattern of fluctuation in this measure, roughly following the pattern shown by the aoristic sums, with a large peak in the Nakabyo and Kasori E phase $\left(t_{8}-t_{15}\right)$ of the Middle Jomon period and during the Horinouchi 1 phase $\left(t_{21}-t_{22}\right)$ of the Late Jomon period, and with the second half of the timesseries showing extremely low values. This suggests a combination of low knowledge and/or a decrease in density for the second half of later Jomon, whereas the comparison of Horinouchi 1 phase peak to the Nakabyo-Kasori E phase is meaningful, with the lower number of pithouses of the former (fig. 3) being confirmed.

From a spatial perspective, the quality of temporal knowledge should ideally be evenly distributed or at least random, but the presence of positive spatial autocorrelation is in practice more likely, due to similar retrieval contexts and strategies within local areas. Several geostatistical methods can provide useful techniques for understanding the spatial distribution of the average aoristic values. For instance figure 5 shows a Getis's Local $G_{i}{ }^{*}(d)$ statistic (Ord and Getis. 1995), a geostatistical local analysis which provides the detection of cold spots (significant clustering of low values) and hot spots (significant clustering of high values). In this case, the southeast portion of the study area appears to be a cold spot, due probably to a high concentration of pithouses attributed to the second half of the Late Jomon period. The exclusion of such areas from some of the spatial analysis suggested below is therefore necessary, especially if higher sample quality is required. 


\subsection{Probabilistic Approaches to diachronic point pattern analysis}

The integration of aoristic probability values as measures of temporal uncertainty allows us to explore two different approaches for identifying the actual spatial pattern of points in each period and their change through time.

The first approach is based on the adoption of weighted spatial analysis, where the probability values are integrated directly into the assessment of the pattern itself. The output will be similar to traditional point pattern approaches (e.g. a numerical value that indicates more or less clustered, random or regular configurations), where the uncertainty is embedded in the final output. A second and alternative approach involves the creation of a large number of hypothetical spatio-temporal patterns, based on the observed distribution of the probability values. In this case, the output will be the distribution of $n$ analytical outputs (identical to the traditional ones, mentioned above) corresponding to the number of simulation runs. All other things being equal, and depending on our levels of temporal knowledge, the results of these runs may be fairly consistent with one another or may exhibit a lot of variation. This simulation-based approach investigates a distribution of possible results in probabilistic terms, with the occurrence of a specific pattern within the $n$ simulations being the probability that such a pattern has indeed occurred.

Both approaches are capable of analysing the first and the second order properties of a spatial distribution (Bailey and Gatrell 1995, Orton 2005). First order properties refers to global trends in a point pattern that are externally induced, such as the clustering of settlements around a particular environmental resource, and are usually assessed by examining large scale variation in the intensity of a pattern. Second order effects refer to properties which are inherent to the process itself, such as interaction between events (e.g. attraction or repulsion), and are usually assessed through the analysis of local deviation (variance) from the average intensity. Most spatial patterns are characterized by both these properties, and identifying the relative importance of each one represents a core aspect of modern point pattern analysis.

\subsubsection{An Uncertainty-Weighting Approach}

Several spatial analysis tools include weighted versions that introduce an intensity value for each point event. The majority are focused on either spatial versions of well-known summary statistics (mean centre of distribution, standard distance; Mitchell 2005) or the assessment of first order properties (kernel density estimates; Baxter et al. 1997). There are a number of alternative tools aimed at assessing second order properties, and capable of integrating weighted values such as weighted $K$ functions (Getis 1984) and pair correlation functions (Gavrikov and Stoyan 1995). However, their underlying assumptions are based on the assessment of the spatial distribution of some variable associated with the point location, rather than the pattern of the point process itself. 
Another crucial feature to note is that these statistical methods treat the value associated with each event as a relative variable with no absolute meaning. This is not a problem in determining the most probable pattern for one specific temporal block, but becomes more of a limitation when quantitative diachronic comparison is required. For instance, figure 6 shows the spatial translation of the aoristically weighted mean centre of distribution. While still providing a useful visual tool for assessing the change in the absolute location of pithouses, it is difficult to assess whether the presence of a trough in the bar chart is related to the actual stability of the first order distribution or rather to a simple absence of information. Clearly a comparison with the summary statistics of aoristic mean/median can partially solve the problem by increasing our critical awareness of the pattern suggested visually. However, the weakness of such a method is still obvious, especially over large spatial and temporal scales where the distribution of our knowledge is likely to be uneven and thus not easily comprehensible. The same problem is evident for any global statistics, since their values are mathematically dependent on the distribution of the observed data, rather than on their actual absolute values. Thus a point pattern $X_{1}$ with all the events associated with a constant aoristic value of 0.1 will produce exactly the same results as a point pattern $\mathrm{X}_{2}$ where the location of the events are identical to $\mathrm{X}_{1}$ but with a constant aoristic value of 0.9 . This is clearly problematic since, diachronic comparison is thereby feasible only for recognizing the most probable pattern, without assessing how statistically likely this is to have occurred (i.e. how probable is the specific pattern).

From this perspective, the most useful tool is perhaps the application of a weighted version of kernel density estimation (see Baxter et al. 1997, Goerlich 2003). The output in this case will represent the density of a point process in probabilistic terms, which in turn can be used as the input data for a wide range of tools grouped under the label of spatial time series analysis. These provide useful visual tools such as temporal profiling (in simple terms, the extraction of linear time series for each sample location), pair-wise comparisons and voxel modelling (Crema forthcoming) all capable, in different ways, of handling large quantities of data either through visual assessment or basic quantitative analysis.

\subsubsection{A Simulation Based Approach}

An alternative and more robust approach relies on the creation of a series of $n$ spatio-temporal distributions based on the probability values defined by the aoristic analysis. Each simulated distribution will be assessed separately and the result expressed as a simplified, categorical outcome (i.e. clustered, uniform or random) for each temporal block. These categorical outcomes can then be combined for the final output, which will return the percentage, and consequently the probability, of each categorical pattern. This type of simulation-based approach, which falls under the general umbrella of Monte Carlo methods (see Robert and Casella 2004 for an introduction), is increasingly common in a variety 
of fields and has potential applications in archaeology for case-specific statistical tests. Examples of such approaches can be found for instance in viewshed analysis, where the observed pattern is compared to the simulated random pattern in order to assess the statistical significance of the distribution (Fisher 1997, Lake and Woodman 2003). However, for the purposes of this paper, the simulated pattern will be pseudo-random as the probabilistic outcome of the aoristic analysis will be used as a constraint in the creation of the spatio-temporal pattern.

For what follows, analytical methods based on Ripley's K functions were written in the $R$ statistical language (www.r-project.org with the additional code available from the corresponding author; for previous archaeological applications of $\mathrm{K}$ functions, see Orton 2005, Bevan and Conolly 2006) and used for the assessment of the second order properties of the pithouse distribution in a small sample area of generally higher aoristic values (figure 2). The aim of this analysis was to determine if the apparent dispersion of pithouses observed towards the end of the Middle Jomon period is statistically relevant, and if it was caused by a change in the nature of the spatial interaction.

As input data, the program requires the spatial location of the point observations, their aoristic values at each timestep, the distance bins for which the $\mathrm{K}$ function is computed, the number of local simulation runs for the confidence envelope in the function and the total number of spatio-temporal processes to be simulated. On the basis of the aoristic distribution (step 1 in figure 7) the program creates a series of simulated spatio-temporal processes (step 2 in figure 7) where the aoristic distribution is substituted for a binary outcome of existence $(w=1)$ or nonexistence $(w=0)$ on the basis of the initial input probability values. Spatio-temporal slots with higher initial aoristic value are thus more likely to be substituted with 1 , while lower values are more likely to be substituted with 0 . Clearly, with all other things being equal (e.g. the temporal duration of the events), each event can only be definitely present or definitely absent and this will create a spatio-temporal pattern for which the temporal knowledge is absolute. For each simulated spatiotemporal distribution, at each timestep, all the events with $w=1$ are inlcuded in the $\mathrm{K}$ function calculation, with a further adjustment for edge effects proposed by Goreaud and Pélissier (1999). Then for each distance bin, the observed K value can be compared to the local spatial simulation envelope (representing a random Poisson process) to indicate the type of pattern that might be present (clustered, uniform or random distribution). The output of these comparisons will be stored as a nominal value for each distance bin, at each timestep. The process is then repeated for each simulation run, and the distribution of outcomes will in turn indicate the probability of the occurrence ${ }^{2}$ of the specific pattern at each spatial scale and timestep (step 3 figure 7).

\footnotetext{
2 It is also possible to obtain two distributions of p-values (one for the clustering test and one for the dispersion test) computed from the spatial Monte Carlo simulation. The resulting distributions of significance values can potentially be combined (providing a single p-value for clustering and a single p-value for dispersion) using Fisher's combined probability test for each distance bin at each time-step. However this approach remains untested, and the implications of such a nested Monte Carlo simulation for such estimates need further evaluation. This topic is therefore of future interest, but outside the scope of the present paper.
} 
The advantage of a simulation-based approach is that it permits the use of any of the spatial statistics proposed by the literature, since it is not limited by the mathematical complications of integrating uncertainty values as variables in the analysis itself. The spatio-temporal patterns created by Monte Carlo simulation are in fact characterized by absolute knowledge in both the spatial and temporal dimension, and are restricted only by the choice of their resolution. The probabilistic output also solves some issues related to the ambiguity of global statistics in a diachronic context, since the uncertainty is embedded in the output. And finally, since the simulation recreates spatio-temporal processes, comparison across time becomes feasible and the use of related methods such as the bivariate or space-time $\mathrm{K}$ functions are possible. Despite its advantages, the simulation approach also has a number of limitations, one of these being the number of simulations necessary to provide a reasonable assessment of the spatio-temporal process. The number of possible combinations of the events is extremely large and it is impossible to compute the analysis for all of these, even with a large cluster of computers. One solution is to compare the pattern produced by each of a different number of simulations in order to assess the optimal number after which the variation of the pattern becomes insignificant.

For the purposes of this paper, a smaller test area was chosen within which high levels of temporal knowledge predominate (figure 2; compare with figure 5), which also covers a smaller chronological range spanning the Middle Jomon period (t1-t20). The following analysis focuses on a distance range between 0 and 200 meters with a bin size of 2 meters, while 500 local spatial simulations have been used to create the confidence envelope. The program has been used three times with 500, 1000 and 5000 temporal simulations. Comparison of the results (figure 8) shows that the outcome is already stable from 500 simulations, indicating that this is sufficient to provide a robust description of the spatio-temporal process.

The results of the analysis have shown an almost complete absence of uniform distributions, with the probability of clustering changing at different scales at different timesteps. Clustering over a probability threshold of 0.5 starts from $t_{8}$ and ends at $t_{15}$ (with probabilities over 0.5 still present at middle distances) and $t_{16}$ (with no clustering with probability higher than 0.1). Figure 9 shows the probability of clustering within $t_{9}$ to $t_{16}$ (Kasori EI to Kasori EIV) at short distances (2-50 meters) and indicates an apparent decrease of clustering probability at short distances, especially after $t_{15}$. This corresponds to the second part of Kasori EIII phase considered by some scholars as crucial point for understanding the transition to the dispersed pattern typical of the pottery phases of final Middle Jomon and Initial Late Jomon period (Kano 2002).

\section{Summary of results}

The probabilistic approach discussed above facilitates the application of several analytical tools that were previously unsuitable or problematic, and enables us to identify novel patterns that are otherwise undetectable with traditional methods 
due to their coarse chronological resolution and their inability to handle sources with varying levels of temporal knowledge.

The analysis of the shift in the mean centre of distribution documented two parallel trends towards the end of the Middle Jomon period, corresponding to time steps $t_{13}-t_{17}$. Firstly, there is a clear shift in the mean centre of distribution towards the southern part of the study area. The distance involved in this process (ca. 500$600 \mathrm{~m}$ ) is only slightly larger than the "shifting distance" described in some ethnographic studies (Wandsnider 1992) and it therefore remains difficult to assess at this stage whether the pattern reflects the re-location of the same community due to local micro-environmental changes or by a gradual abandonment of a group and the arrival of new communities in new locations during the Late Jomon period. Evidence for sea-level changes during the Middle Jomon to Late Jomon transition that may well have changed the distribution of local maritime resources (Sugihara 1988), as well as for external cultural influences on local pottery styles in the same period (Kano 2002) can be used to support either arguments to different degrees, and ultimately indicates the need for future comparison of several case studies.

The second aspect illustrated by the analysis above is an increase in the distance of mean centre shifts between timesteps $t_{13}$ and $t_{17}$. One possible cause of this pattern is the reduction of what Dewar and McBride (1992:231-237) define as 'spatial congruence', in which case the large distance in the shift of the mean centre of distribution is in fact due to an unwillingness on the part of inhabitants to relocate new residential units in the same place as previous once and can thus be related to a relatively short period of occupation in any one place.

The results of the $\mathrm{K}$ function analysis partly support the latter argument, with a clear increase in the probability that the residential units within each time-block have neither patterns of aggregation nor of segregation. From a statistical viewpoint this implies a lack of spatial dependence in the underlying point process (i.e. the one generating the observed distribution of settlements) and means that the construction of each residential unit is not in turn influenced by the presence of other residential units from the same time-block. If we consider the use-life of these pithouses as suggested by the literature (e.g. Watanabe 1986) and the length of our time-blocks, there are chances that the pattern reflects multiple short occupations occurring at different times within the time-block itself. Divergence in the season of occupation of two pithouses, deduced from the analysis of shell deposits supports this hypothesis (Toizumi 2007), but further investigation, which integrates additional variables (such as the facility depletion interval: Wandsnider 1992), should be undertaken, since the visible remains of abandoned residential units are still likely to have had some influence on the location of new pithouses. Alternatively, the occurrence of radically opposing patterns for two different moments of time within a time-block might also produce a random pattern in the archaeologically observed data. Such scenario is less likely to have occurred, since a high degree of spatio-temporal non-stationarity will indicate different interaction properties (e.g. attraction and repulsion) among the residential units through and within multiple time-steps. This will in fact happen only if the cycles of change 
between clustered and dispersed patterns have a higher frequency compared to the achievable temporal resolution.

The possible increase in the residential mobility, suggested above, is not a unique episode within the Jomon period. Such changes have in fact been suggested for the end of the Early Jomon Period (Habu 2001), the transition to the Late Jomon period, and during the second half of the Late Jomon period (Nishino 2005), indicating the existence of potential cyclical events in the spatio-temporal organization of these complex hunter-gatherer communities.

\section{Discussion}

The importance of integrating the temporal component into archaeological spatial analysis is not merely limited to its role in diachronic comparison, but also in our basic assessment of spatial patterning in the first place. The formal quantification of temporal uncertainty is therefore a fundamental issue, which requires further investigation in order to exploit all available archaeological knowledge. On the other hand, it is important to remember that there are intrinsic limits to what kinds of research questions can be asked in cases where our chronological knowledge is less than perfect. Extremely fine-grained subdivision of the temporal dimension will produce a 'flat' diachronic pattern in most cases, with probability values spread fairly evenly across the timesteps, and the impression of a rather static spatio-temporal pattern. The main aim and the most useful outcome of the probabilistic approach is not to create new information, but rather to make best use of the available information by integrating different degrees of knowledge. In general, such approaches will require a more sophisticated and advanced set of techniques that are capable of managing and integrating different types of knowledge, such as probabilistic information (e.g. aoristic analysis or radiocarbon dates), temporal topology (e.g. stratigraphic relationships) or even intuitive knowledge, ultimately structured in a complex epistemological environment characterized by a network of ranked and ordered relationships between different temporal ontologies. The increasing use of Bayesian statistics (e.g. Buck et al. 1996), Dempster-Shafer theory (e.g. Ejstrud 2005) and fuzzy logic (e.g. Hatzinikolaou 2006) all aim to manage large amounts of spatial and temporal multivariate data characterized by different degrees of uncertainty, and appear to be promising research directions.

Ultimately the goal of an aoristic and probabilistic approach is to reduce, as part of the interpretative process, the possible alternative patterns that might occur within a specific temporal block. The output will thus not be to propose a single solution (a single pattern) but rather an environment where comparisons between alternative hypotheses are made easier. A simulation-based approach offers great opportunities for retrieving such information while retaining a clear idea of available temporal knowledge; it also offers a chance to create case-specific analytical tools, which can integrate time as a proper dimension, rather than as an attribute of singular events. Finally, both the mathematical formality of the 
probabilistic approach and the integration of a temporal dimension will require a more sophisticated and formal definition of the unit of analysis. This is especially the case for the aggregated, subjectively defined and ontologically unstable types of event such as 'site' or 'settlement' on which most archaeological spatial analysis is focused. The adoption of probability weights for units with more ontologically consistent boundaries addresses this issue by simply avoiding the problems associated with the definition of aggregate units (for an example where the probability weights have been assigned to each retrieved artefact, see Bevan et al. 2008:33; and for the datasets: www.ucl.ac.uk/asp/). The formal and quantitative integration of complex elements such as duration or the ontological transformations of the events (e.g. different functions for a site over time and their resulting unsuitability as units of analysis for specific questions) are the most difficult issues to be faced, since they alter the dimensionality of the events themselves. These units of analysis cannot be described as one-dimensional points in a multidimensional space, but rather as multidimensional entities in a multidimensional framework. Any spatial analysis which seeks to provide a proper insight into changing patterns through time will thus require the construction of both new theoretical perspectives and new methodological tools.

\section{Acknowledgments}

Our thanks to Clive Orton for encouragement and advice on many methodological and theoretical issues relevant to this paper. EC is also grateful for the many hours of discussion spent with Masahito Nishino on aspects of the research question and the case study. Special thanks goes also to the anonymous reviewers, whose comments and suggestions improved the paper and indicated future directions of inquiry. The spatial analysis was conducted in ESRI ArcGIS 9.1 and GRASS 6.3, while the R statistical environment was used for the spatio-temporal Monte Carlo method, partly based on the add-on packages, ads (Pelissier and Goreaud, 2008) spatstat (Baddeley and Turner, 2005) and car (Fox, 2008). The dataset used for the case study has been kindly provided by the Cultural Properties Centre of the Chiba Prefecture Education Foundation. This work was also possible thanks to the support of the AHRC Centre for the Evolution of Cultural Diversity and an award of a UCL Graduate Research Scholarship to EC. 


\section{Figures}

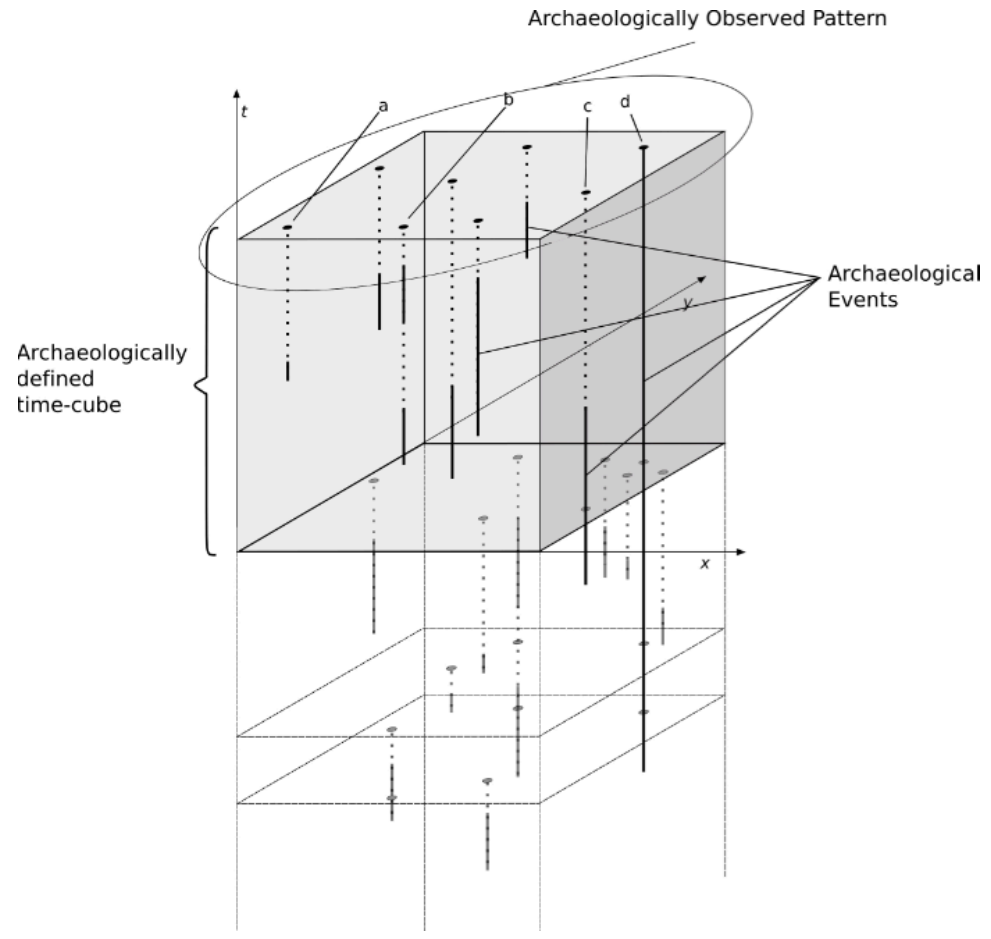

Figure 1. A three dimensional schematic representation of a spatio-temporal process. The archaeologically observed pattern is the projection of different archaeological events in a bidimensional plane determined by a time-cube bounding a portion of space-time. Since the observed pattern is a mere projection, information regarding the spatio-temporal processes within the timecube is lost. Events occurring once (a), in multiple episodes (b), in more than one time-cubes (c) or lasting for the entire existence of the specific time-cube (d) are all treated equally within the bidimensional representation of the archaeologically observed pattern. 


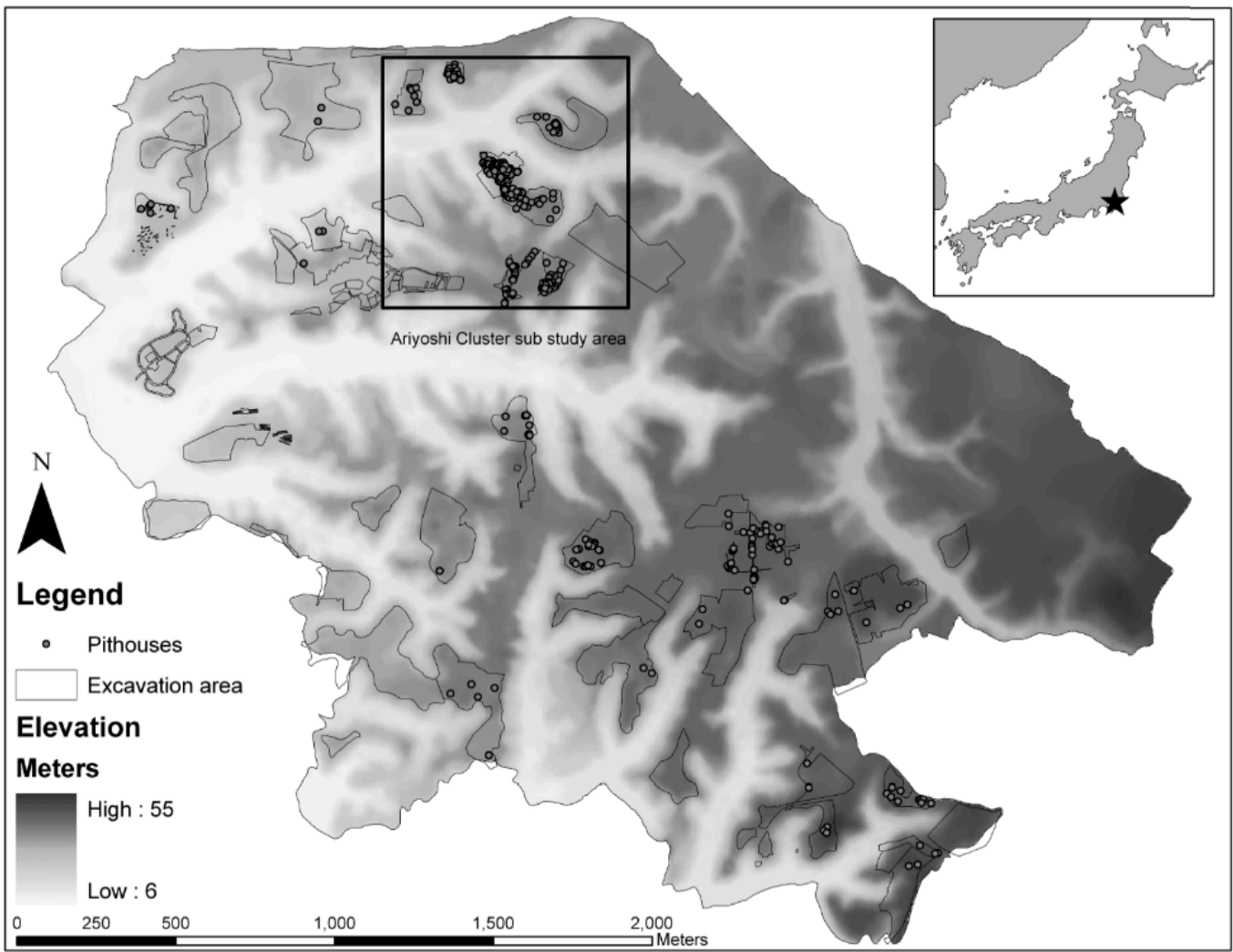

Figure 2. The case study area and the sub-sample dataset used for Monte Carlo simulation.
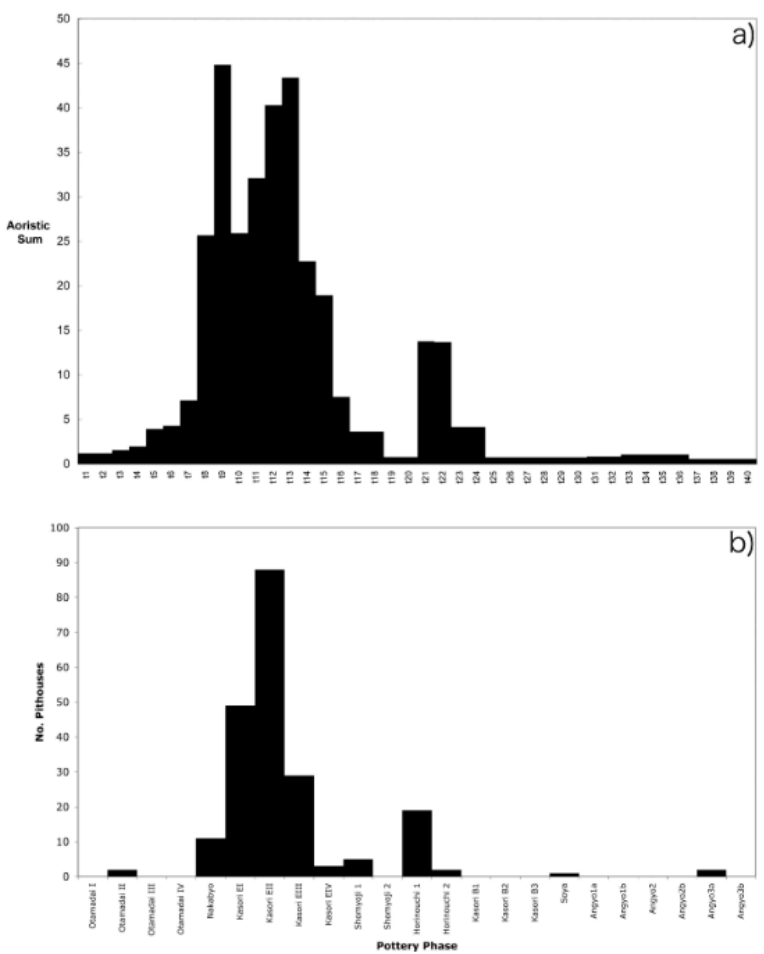

Figure 3. The sum of aoristic weights for each timestep(a). No of pithouses for each pottery phase (b). 


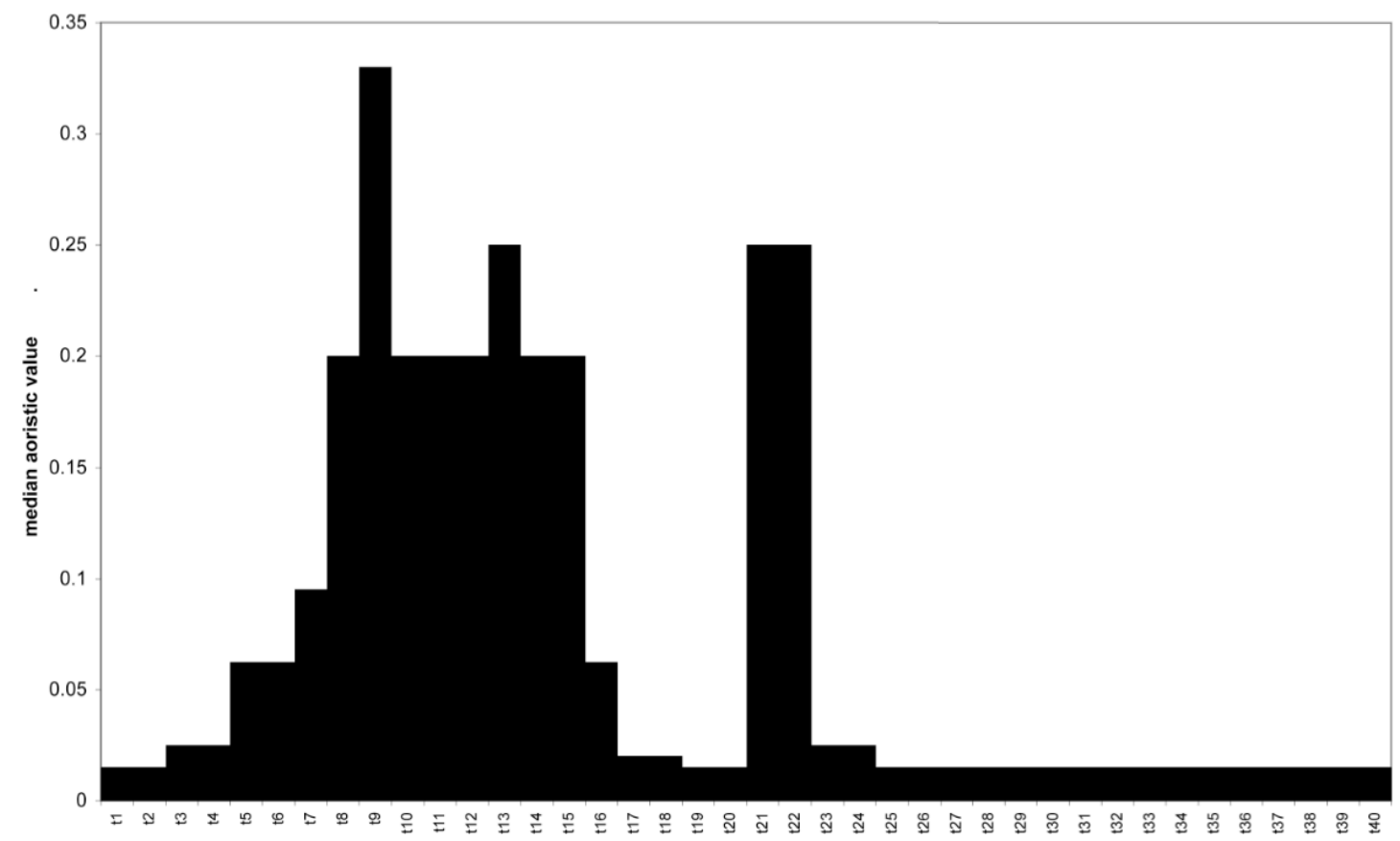

Figure 4. The aoristic median of each timestep indicating the degree of temporal knowledge for each time-step.

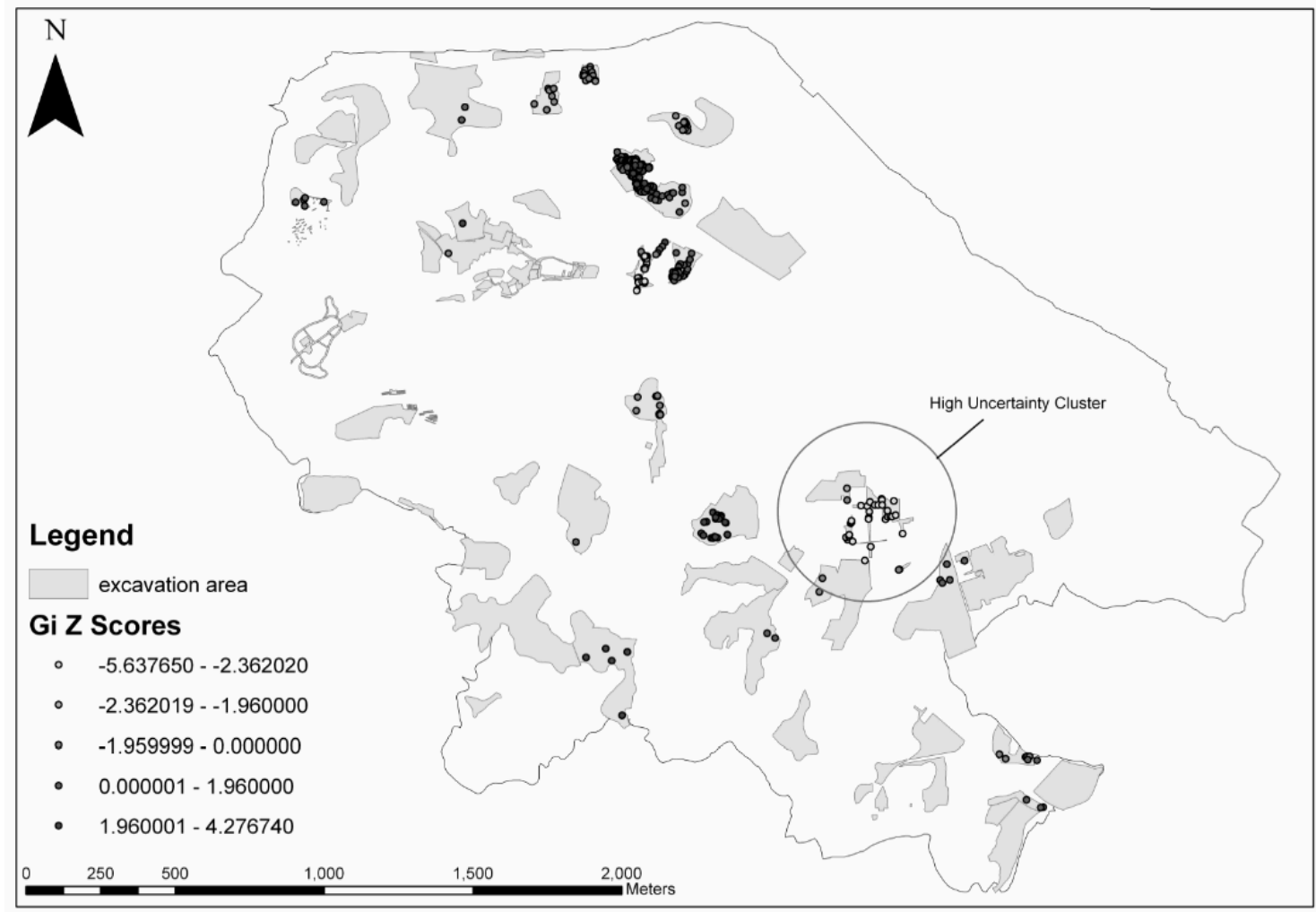

Figure 5. A local $\mathrm{G}_{\mathrm{i}}{ }^{*}(\mathrm{~d})$ statistic assessing the local clustering of high/low mean aoristic values (distance bandwidth=100 m). 

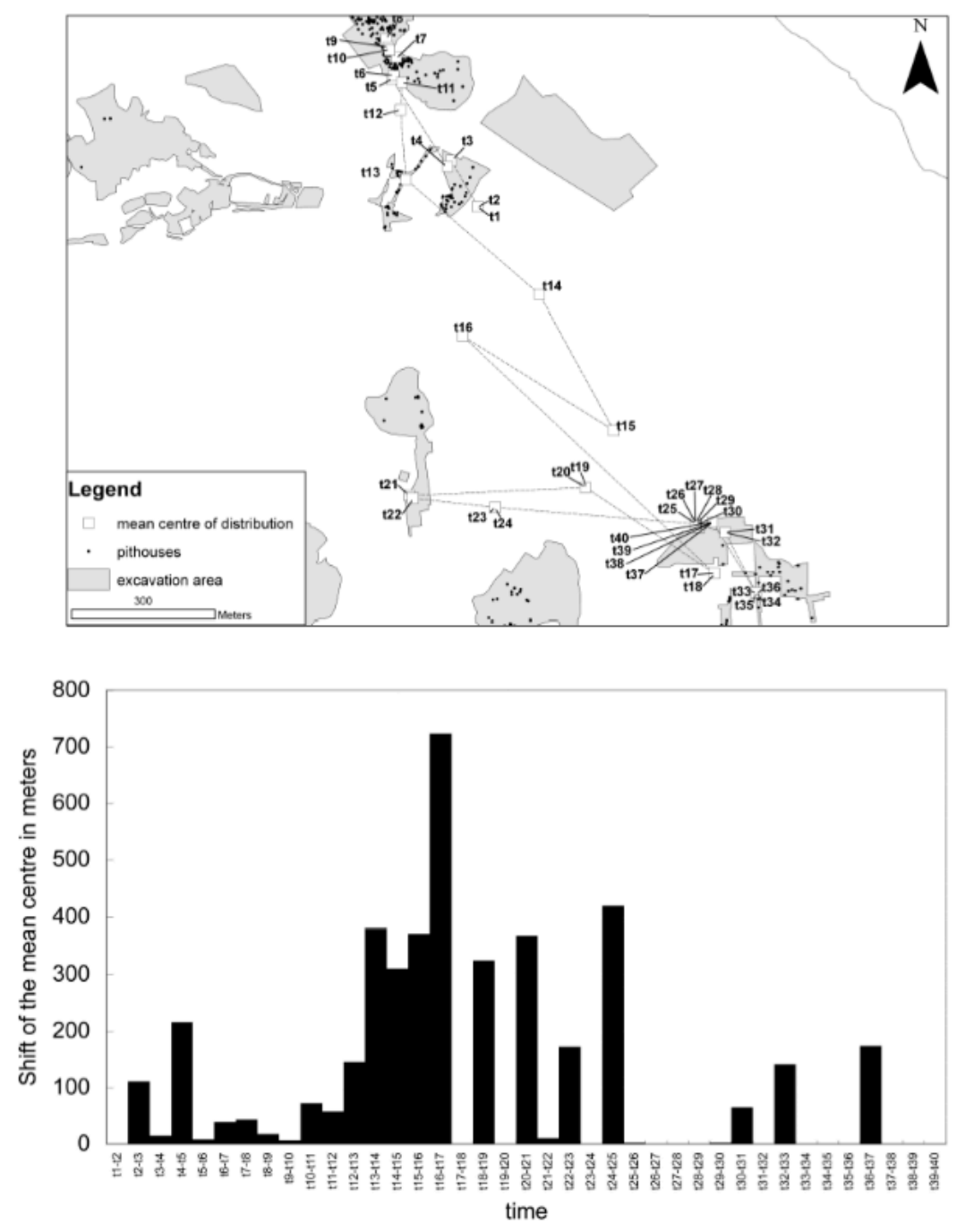

Figure 6 . The shift in the aoristically weighted mean centre of distribution indicating the global change of first order properties in the study area (above). The length of the mean centre of distribution shift of consecutive time steps, (below). 

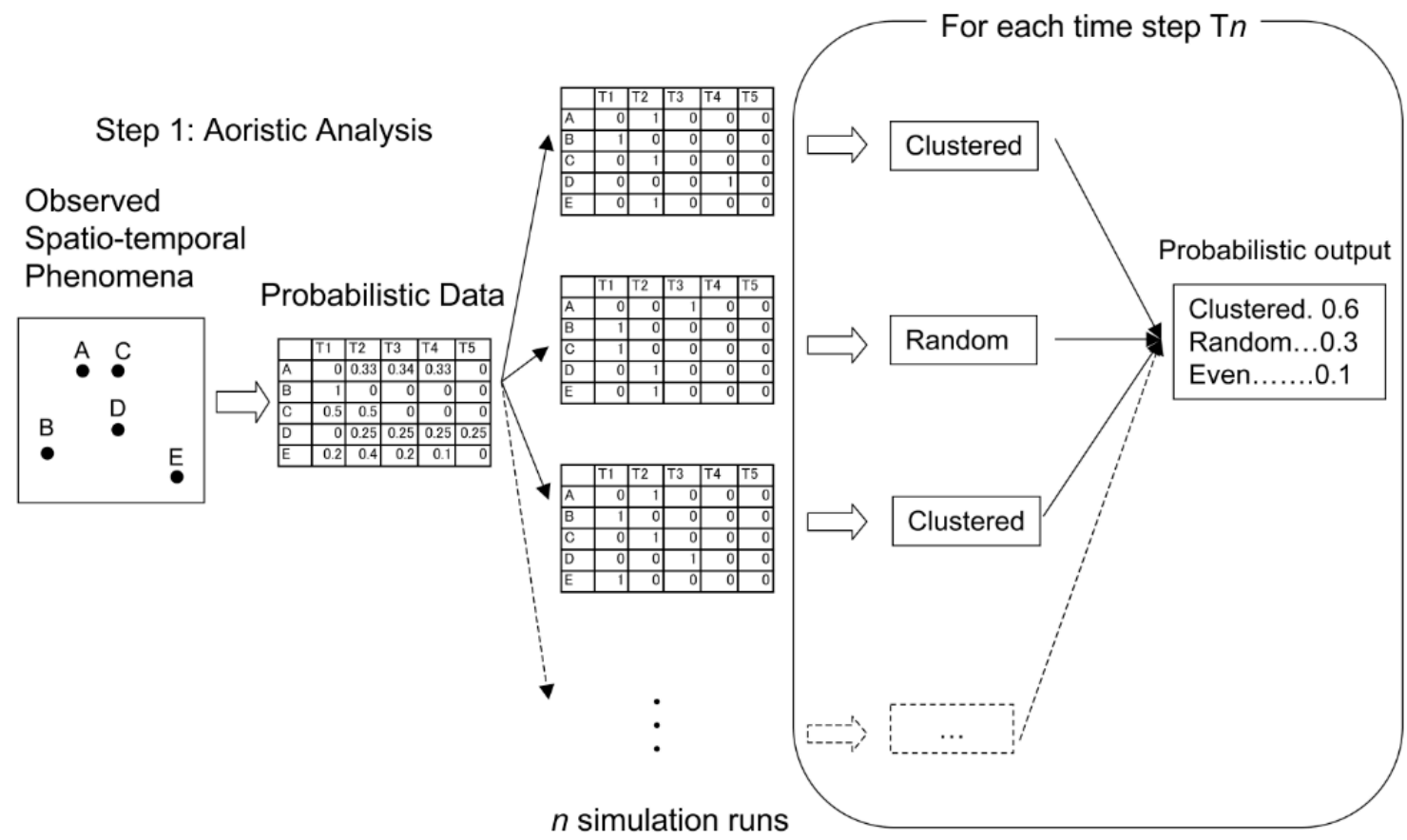

Step 3: Spatial Analysis

Figure 7. An example of an analysis using Monte-Carlo simulation of a spatio temporal pattern. The observed spatio-temporal data is firstly converted to aoristic data (step 1), then a series of simulated spatio-temporal patterns are created (step 2). Finally each of these patterns is assessed and the results are stored in order to provide a probabilistic output to the analysis (step 3).

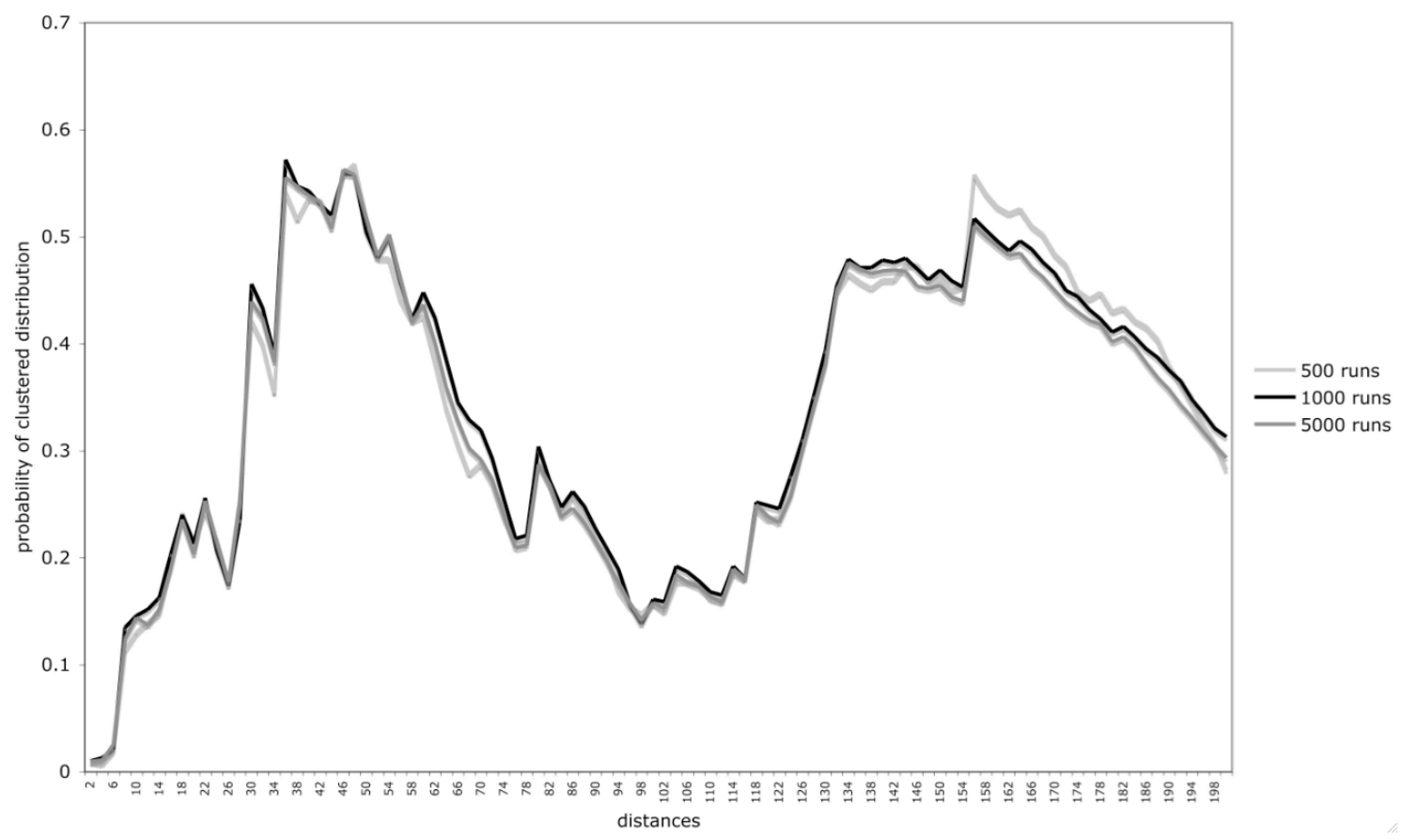

Figure 8. Comparison of 500, 1000 and 5000 simulation runs for the Monte Carlo simulation based Ripley's K Function. The lines represent the probability of clustering at increasing distances for the $\mathrm{t}_{15}$. 


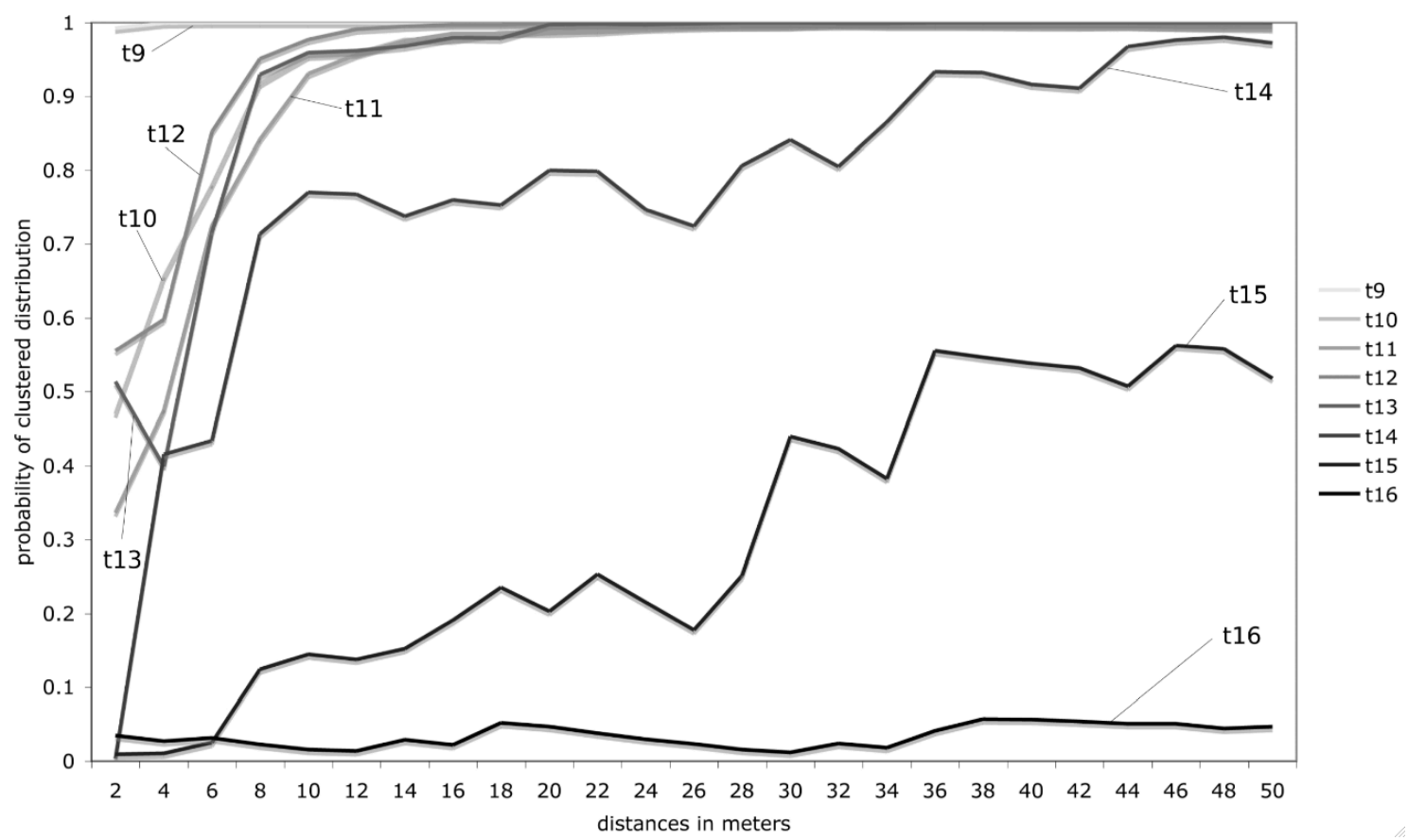

Figure 9. Comparison of clustering probability at short distances (2-50 meters) from to to $\mathrm{t}_{16}$ (Kasori EI to Kasori EIV phase). Initially, clustering occurs at short distances between 2 and 4 meters $\left(t_{9}-t_{13}\right)$, then the pattern at low distances becomes increasing random until $t_{16}$ when no clustering occurs at the first 50 meters. 


\section{References}

Baddeley, A.,Turner, R. 2005. Spatstat: an $R$ package for analyzing spatial point patterns. Journal of Statistical Software 12,1-42.

Bailey, T.,C., Gatrell, A.C., 1995. Interactive Spatial Data Analysis. Longmans Scientific \& Technical, Harlow.

Baxter, M.J., Beardah, C.C., Wright, R.V.S., 1997. Some Archaeological Applications of Kernel Density Estimates, Journal of Archaeological Science. 24, 347-354

Bevan, A., Conolly, J., 2006. Multiscalar Approaches to Settlement Pattern Analysis. In: Lock, G., Molyneaux, B. (Eds.), Confronting Scale in Archaeology: Issues of Theory and Practice. Springer, New York, pp. 217-234.

Bevan, A., Conolly, J., Tsaravopoulos, A., 2008. The fragile communities of Antikythera. Archaeology International. 10, 32-36.

Bevan, A. and Connolly, J., 2009. Modelling Spatial Heterogeneity and Nonstationarity in Artifact-Rich Landscapes. Journal of Archaeological Science. 36, 956-964.

Buck, C.E., Cavanagh, W.G., Litton, C., 1996. Bayesian Approach to Intrepreting Archaeological Data. Wiley, Chirchester.

Castleford, J., 1992. Archaeology, GIS, and the time dimension: an overview. In: G. Lock, G. and Moffett, J. (Eds.), Computer Applications and Quantitative Methods in Archaeology 1991. BAR International Series S577.Tempvus Reparatvm, Oxford, pp.95-106.

Crema, E.R., forthcoming. Aoristic Approaches and Voxel Models for Spatial Analysis, In Proceedings of the $36^{\text {th }}$ Annual Conference on Computer Applications and Quantitative Methods in Archaeology, Budapest, 2-6 April 2008.

Daly, P. T. and Lock, G. 1999. Timing is everything: Commentary on managing Temporal Variables in Geographic Information Systems. Barceló, J. A., Briz, I., Vila, A. (Eds.), New Techniques for Old Times CAA98. Bar International Series 757. Archaeopress, Oxford, pp. 259-263.

Dewar, R. E. and McBride, K. A., 1992. Remnant Settlement Patterns. Rossignol, J. and Wandsnider, L. (eds.) Space, time, and archaeological landscapes. Plenum Press, New York, pp. 257-282.

Ejstrud, B., 2005. Taphonomic Models: Using Dempster-Shafer theory to assess the quality of archaeological data and indicative models. In: Van Leusen, M., Kamermans, H. (Eds.), Predictive Modelling for Archaeological Heritage Management: A research agenda. NAR 29. ROB, Amersfoort, pp. 183-194. 
Fisher, P., Farrelly, C., Maddocks, A., Ruggles, C., 1997. Spatial Analysis of Visible Areas from the Bronze Age Cairns of Mull. Journal of Archaeological Science. 24, 581-592.

Fox, J. 2008. The car Package. R Foundation for Statistical Computing.

Gavrikov, V., Stoyan, D., 1995. The use of marked point processes in ecological and environmental forest studies. In Environmental and Ecological Statistics. 2, 331-344.

Getis, A., 1984. Interaction modeling using second-order analysis. Environment and

Planning A. 16, 173-183.

Goerlich, F. J., 2003. Weighted samples, kernel density estimators and convergence. Empirical Economics. 28,335-351.

Goreaud, F., Pélissier, R., 1999. On Explicit Formulas of Edge Correction for Ripley's K-Function. Journal of Vegetation Science. 10, 433-438.

Habu, J. 2001. Subsistence-Settlement Systems and Intersite Variability in the Moroiso Phase of the Early Jomon Period of Japan. International Monographs in Prehistory, Ann Arbor.

Habu, J., 2004. Ancient Jomon of Japan. University of Cambridge Press, Cambridge.

Habu, J., 2008, Growth and decline in complex hunter-gatherer societies: a case study from the Jomon period Sannai Maruyama site, Japan. Antiquity. 82, 571-584.

Hatzinikolaou, E., 2006. Quantitative Methods in Archaeological Prediction: From Binary to Fuzzy Logic. In: Mehrer, M., Wescott, K. (Eds.), GIS and Archaeological Site Location Modeling. CRC Press, Boca Raton, pp. 437-446.

Imamura, K., 1996. Prehistoric Japan: New perspectives on insular East Asia. UCL Press, London

Johnson, I., 2004. Aoristic Analysis: seeds of a new approach to mapping archaeological distributions through time. In Ausserer, K.F., Börner, W., Goriany, M. and Karlhuber-Vöckl, L. (Eds), [Enter the Past] The E-way into the Four Dimensions of Cultural Heritage: CAA2003. BAR International Series 1227. Archaeopress, Oxford, pp. 448-452.

Kano, M., 2002. Hikyojyuuikihe no Bunsannkyojyuu ga shimesu shyakai. In: Anzai, M. (Ed.) Jomonshakairon (jo). Douseisha, Tokyo, pp. 235-258 (In Japanese)

Kobayashi, K., 2004. Jomonshakaikenkyu no shishiten: tanso14nendaisokutei no 
riyo. Rokuichishobo, Tokyo. (In Japanese)

Lake, M.W., Woodman, P.E., 2003. Visibility studies in archaeology: a review and case study. Environment and Planning B: Planning and Design. 30, 689-707.

Lock, G., Harris, D., 2002. Analysing change through time within a cultural landscape: conceptual and functional limitations of a GIS approach. In: Sinclair, P. (Ed.), The Development of Urbanism from a Global Perspective. Uppsala Universitet, Uppsala. Retrived $10^{\text {th }}$ November 2007 from World Wide Web: http://www.arkeologi.uu.se/afr/projects/BOOK/contents.htm

Minami, H., 2002. Hennenhyo to Kasetsunendai: Hoshaseitansonendainomae ni. Kodai. 111, 85-93. (In Japanese).

Mitchell, A., 2005. The ESRI Guide to GIS Analysis, Volume 2: Spatial Measurements and Statistics. ESRI Press, New York.

Nishino, M., 2005, Tokyowanhigashigan no oogatakaizuka wo sasaeta Seisankyoujyuyoshiki. Chiiki to Bunka no Koukogaku, I, Department of Archaeology, Meiji University, Tokyo, pp. 695-711.

Ord, J. K., Getis, A., 1995. Local Spatial Autocorrelation Statistics: Distribution Issues and an Application. Geographic Analysis. 27, 286-306.

Orton, C., 2000. Sampling in Archaeology. Cambridge University Press, Cambridge.

Orton, C., 2005. Point Pattern Analysis Revisited. Archeologia e Calcolatori. 15, 299-315.

Pelissier, R., Goreaud, F. 2008. The ads Package. R Foundation for Statistical Computing.

Sugihara, S., 1988. Chibashifukin ni okeru jomonjidai no kaigansen no ichi to kochiri.

Chibashiritsukasorikaizukahakubutsukan (ed.) Chibashiritsu kasorikaizuka hakubutsukan Kaikan 20shuunennkinen tokubetsukouzakouenshu. Chibashiritsu Kasorikaizuka Hakubutsukan, Chiba, pp. 189-206.

Toizumi, T., 2007. Kaigara seichosen kara mita jomonshutaku no keisei. Kokogaku Journal. 573, 9-13. (In Japanese with English Title).

Ratcliffe, J. H., 2000. Aoristic analysis: the spatial interpretation of unspecifed temporal events. International Journal of Geographical Information Science. 14, 669-679.

Robert, C. P., Casella, G., 2004. Monte Carlo Statistical Methods, second Ed. 
Springer, New York.

Wandsnider, L., 1992. The Spatial Dimension of Time. Rossignol, J., Wandsnider, L. (eds.) Space, time, and archaeological landscapes. Plenum Press, New York, pp. 257-282.

Watanabe, H., 1986. Community Habitation and Food Gathering in Prehistoric Japan: An Ethnographic Interpretation of the Archaeological Evidence. In: Pearson, R. J., Barnes, G. L., Hutterer, K. L. (Eds.), Windows on the Japanese Past: Studies in Archaeology and Prehistory. Centre for Japanese Studies University of Michigan, Ann Arbor, pp. 229-254. 


\section{Appendix A}

\section{List of excavation reports}

Chibaken Bunkazai Sentaa [Centre of Cultural Heritage of Chiba Prefecture], 1975, ChibaTonanbuNewTown [Chiba SouthEast New Town], vol. 1: Shiinazakikofungun (daiichijichosa), Chiba: Nihonjutakukoudanshutoentakuchikaihatsuhonbu.

Chibaken Bunkazai Sentaa [Centre of Cultural Heritage of Chiba Prefecture], 1975, ChibaTonanbuNewTown [Chiba SouthEast New Town], vol. 2: Kidosakuiseki (daiichijichosa), Chiba: Nihonjutakukoudanshutoentakuchikaihatsuhonbu.

Chibaken Bunkazai Sentaa [Centre of Cultural Heritage of Chiba Prefecture], 1975, ChibaTonanbuNewTown [Chiba SouthEast New Town], vol. 3: Ariyoshiiseki (daiichijichosa), Chiba: Nihonjutakukoudanshutoentakuchikaihatsuhonbu.

Chibaken Bunkazai Sentaa [Centre of Cultural Heritage of Chiba Prefecture], 1977, ChibaTonanbuNewTown [Chiba SouthEast New Town], vol. 4: Oihamakofungun, Chiba: Nihonjutakukoudanshutoentakuchikaihatsuhonbu.

Chibaken Bunkazai Sentaa [Centre of Cultural Heritage of Chiba Prefecture], 1978, ChibaTonanbuNewTown [Chiba SouthEast New Town], vol. 5: Ariyoshiiskei (dainijichosa), Chiba: Nihonjutakukoudanshutoentakuchikaihatsuhonbu.

Chibaken Bunkazai Sentaa [Centre of Cultural Heritage of Chiba Prefecture], 1979, ChibaTonanbuNewTown [Chiba SouthEast New Town], vol. 6: Shiinazakiiseki, Chiba: Nihonjutakukoudanshutoentakuchikaihatsuhonbu.

Chibaken Bunkazai Sentaa [Centre of Cultural Heritage of Chiba Prefecture], 1979, ChibaTonanbuNewTown [Chiba SouthEast New Town], vol. 7: Kidosakuiseki, Chiba: Chibaken Bunkazai Sentaa.

Chibaken Bunkazai Sentaa [Centre of Cultural Heritage of Chiba Prefecture], 1979, ChibaTonanbuNewTown [Chiba SouthEast New Town], vol. 8: Mukoarakuiseki, Kokanzawakofungun, Chiba: Chibaken Bunkazai Sentaa.

Chibaken Bunkazai Sentaa [Centre of Cultural Heritage of Chiba Prefecture], 1980, ChibaTonanbuNewTown [Chiba SouthEast New Town], vol. 9: Rokustssuiseki, Ootsukadai iseki, Chiba: Chibaken Bunkazai Sentaa.

Chibaken Bunkazai Sentaa [Centre of Cultural Heritage of Chiba Prefecture], 1982, ChibaTonanbuNewTown [Chiba SouthEast New Town], vol. 10: Kokanzawakaizuka, Chiba: Chibaken Bunkazai Sentaa.

Chibaken Bunkazai Sentaa [Centre of Cultural Heritage of Chiba Prefecture], 1981, ChibaTonanbuNewTown [Chiba SouthEast New Town], vol. 11: 
Rokutsuukaneyamaiseki, Chiba: Nihonjutakukoudanshutoentakuchikaihatsuhonbu.

Chibaken Bunkazai Sentaa [Centre of Cultural Heritage of Chiba Prefecture], 1983, ChibaTonanbuNewTown [Chiba SouthEast New Town], vol. 12:

Minamifutaeboriiseki, Tokyo: Jutaku Toshiseibikoudanshutoentoshikaihatsuhonbu. Chibaken Bunkazai Sentaa [Centre of Cultural Heritage of Chiba Prefecture], 1982, ChibaTonanbuNewTown [Chiba SouthEast New Town], vol. 13:

Kamiakatsukaichigofun, Kitsunezukakofungun Tokyo: Jutaku Toshiseibikoudanshutoentoshikaihatsuhonbu.

Chibaken Bunkazai Sentaa [Centre of Cultural Heritage of Chiba Prefecture], 1983, ChibaTonanbuNewTown [Chiba SouthEast New Town], vol. 14: Bakuchianaiseki, Ariyoshiiseki (daisanji), Ariyoshiminamiiseki, Tokyo: Jutaku Toshiseibikoudanshutoentoshikaihatsuhonbu.

Chibaken Bunkazai Sentaa [Centre of Cultural Heritage of Chiba Prefecture], 1984, ChibaTonanbuNewTown [Chiba SouthEast New Town], vol. 15: Umanokuchiiseki, Ariyoshijoato, Shiratoridaisiseki. Tokyo: Jutaku

Toshiseibikoudanshutoentoshikaihatsuhonbu.

Chibaken Bunkazai Sentaa [Centre of Cultural Heritage of Chiba Prefecture], 1985, ChibaTonanbuNewTown [Chiba SouthEast New Town], vol. 16: Daizennokitaiseki, Tokyo: Jutaku Toshiseibikoudanshutoentoshikaihatsuhonbu.

Chibaken Bunkazai Sentaa [Centre of Cultural Heritage of Chiba Prefecture], 1990, ChibaTonanbuNewTown [Chiba SouthEast New Town], vol. 17: Takazawaiseki, Tokyo: Jutaku Toshiseibikoudanshutoentoshikaihatsuhonbu.

Chibaken Bunkazai Sentaa [Centre of Cultural Heritage of Chiba Prefecture], 1993, ChibaTonanbuNewTown [Chiba SouthEast New Town], vol. 18: Kamatoriiseki, Tokyo: Jutaku Toshiseibikoudanshutoentoshikaihatsuhonbu.

Chibaken Bunkazai Sentaa [Centre of Cultural Heritage of Chiba Prefecture], 1998, ChibaTonanbuNewTown [Chiba SouthEast New Town], vol. 19: Ariyoshikitakaizuka 1, Chiba: Jutaku Toshiseibikoudanchibachiikishisha.

Chibaken Bunkazai Sentaa [Centre of Cultural Heritage of Chiba Prefecture], 1998, ChibaTonanbuNewTown [Chiba SouthEast New Town], vol. 20: Ariyoshikitakaizuka 2 (Kofunjidaiiko), Chiba: Jutaku Toshiseibikoudanchibachiikishisha.

Chibaken Bunkazai Sentaa [Centre of Cultural Heritage of Chiba Prefecture], 1999, ChibaTonanbuNewTown [Chiba SouthEast New Town], vol. 21: Ariyoshiiseki, Chiba: Jutaku Toshiseibikoudanchibachiikishisha.

Chibaken Bunkazai Sentaa [Centre of Cultural Heritage of Chiba Prefecture], 1999, ChibaTonanbuNewTown [Chiba SouthEast New Town], vol. 22: Kamatoribadaiiseki, Chiba: Jutaku Toshiseibikoudanchibachiikishisha. 
Chibaken Bunkazai Sentaa [Centre of Cultural Heritage of Chiba Prefecture], 2001, ChibaTonanbuNewTown [Chiba SouthEast New Town], vol. 23: Tadahoushiiseki, Chiba: Toshikibanseibikoudanchibachiikishisha.

Chibaken Bunkazai Sentaa [Centre of Cultural Heritage of Chiba Prefecture], 2002, ChibaTonanbuNewTown [Chiba SouthEast New Town], vol. 24: Tomiokakofungun, TomiokakofunBshigun Chiba: Toshikibanseibikoudanchibachiikishisha.

Chibaken Bunkazai Sentaa [Centre of Cultural Heritage of Chiba Prefecture], 2002, ChibaTonanbuNewTown [Chiba SouthEast New Town], vol. 25: Ariyoshijo. Chiba: Toshikibanseibikoudanchibachiikishisha.

Chibaken Bunkazai Sentaa [Centre of Cultural Heritage of Chiba Prefecture], 2002, ChibaTonanbuNewTown [Chiba SouthEast New Town], vol. 26: Shiinajinjaiseki, Koshirokoyumiiseki, Rokutsuujinjaminamiiseki, Ootsukadaiiseki. Chiba:

Toshikibanseibikoudanchibachiikishisha.

Chibaken Bunkazai Sentaa [Centre of Cultural Heritage of Chiba Prefecture], 2003, ChibaTonanbuNewTown [Chiba SouthEast New Town], vol. 27: Kasugasakuiseki. Chiba: Toshikibanseibikoudanchibachiikishisha.

Chibaken Bunkazai Sentaa [Centre of Cultural Heritage of Chiba Prefecture], 2004, ChibaTonanbuNewTown [Chiba SouthEast New Town], vol. 28: Imadaiiseki. Chiba: Toshikibanseibikoudanchibachiikishisha.

Chibaken Bunkazai Sentaa [Centre of Cultural Heritage of Chiba Prefecture], 2004, ChibaTonanbuNewTown [Chiba SouthEast New Town], vol. 29: Bakuchianaiseki, Daizennominamikaizuka, Ariyoshijoato (kyusekkijidai). Chiba:

Toshikibanseibikoudanchibachiikishisha.

Chibaken Bunkazai Sentaa [Centre of Cultural Heritage of Chiba Prefecture], 2004, ChibaTonanbuNewTown [Chiba SouthEast New Town], vol. 30: Ojinadaiiseki.

Chiba:Toshisaiseikikochibachiikishisha.

Chibaken Bunkazai Sentaa [Centre of Cultural Heritage of Chiba Prefecture], 2005, ChibaTonanbuNewTown [Chiba SouthEast New Town], vol. 31: Mukoarakuiseki2, Mukoaraku10gokofun, Kamiakatsukaiseki. Chiba: Toshisaiseikikochibachiikishisha.

Chibaken Bunkazai Sentaa [Centre of Cultural Heritage of Chiba Prefecture], 2005, ChibaTonanbuNewTown [Chiba SouthEast New Town], vol. 32:Kokanzawakofungun. Chiba:Toshisaiseikikochibachiikishisha.

Chibaken Bunkazai Sentaa [Centre of Cultural Heritage of Chiba Prefecture], 2005, ChibaTonanbuNewTown [Chiba SouthEast New Town], vol. 33:ShiinazakikofunggunCshigun. Chiba: Toshisaiseikikochibachiikishisha. 
Chibakenkyouikuinkai [Board of Education of Chiba], 1999.

Chibakenmaizōubunkazaibunpuchizu (3) - Chiba/Ichihara/Nagnouchiku (Kaiteiban)

[Distrubutional Map of cultural heritage and monuments of Chiba prefecture 3,

Chiba/Ichihara/Nagnouchiku (Revised version)]

Chibakenkyoikushinkozaidan [Chiba Prefectural Education Foundation], 2006, ChibaTonanbuNewTown [Chiba SouthEast New Town], vol. 34: Shironodaiiseki.

Chiba: Toshisaiseikikochibachiikishisha.

Chibakenkyoikushinkozaidan [Chiba Prefectural Education Foundation], 2006, ChibaTonanbuNewTown [Chiba SouthEast New Town], vol. 35:

ShiinazakikofungunBshigun. Chiba: Toshisaiseikikochibachiikishisha.

Chibakenkyoikushinkozaidan [Chiba Prefectural Education Foundation], 2006, ChibaTonanbuNewTown [Chiba SouthEast New Town], vol. 35: Shironodaiiseki.

Chiba: Toshisaiseikikochibachiikishisha.

Chibakenkyoikushinkozaidan [Chiba Prefectural Education Foundation], 2007, ChibaTonanbuNewTown [Chiba SouthEast New Town], vol. 36: Jinmeijinjaiseki.

Chiba: Toshisaiseikikochibachiikishisha.

Chibakenkyoikushinkozaidan [Chiba Prefectural Education Foundation], 2007, ChibaTonanbuNewTown [Chiba SouthEast New Town], vol. 37: Rokutsuukaizuka. Chiba: Toshisaiseikikochibachiikishisha.

Chibakenkyoikushinkozaidan [Chiba Prefectural Education Foundation], In press, ChibaTonanbuNewTown [Chiba SouthEast New Town], vol. 40:

Ariyoshiminamikaizuka. 